\title{
ANÁLISE CRÍTICA DAS CONTRIBUIÇÕES \\ DAS TESES BRASILEIRAS SOBRE O TEMA DE REDES
}

\author{
A CRITICAL ANALYSIS OF THE CONTRIBUTIONS \\ MADE BY BRAZILIAN THESES ON THE TOPIC OF NETWORKS
}

Recebido em: $11 / 08 / 2014 \cdot$ Aprovado em: $23 / 10 / 2014$
Avaliado pelo sistema double blind review
Editora Científica: Manolita Correia Lima
DOI: $10.13058 /$ raep.2015.v16n1.200

\section{EDUARDO JORGE BRANCO VIEIRA BARCELOS eduardobrancobarcelos@gmail.com \\ RICARDO LERCHE ELEUTÉRIO \\ ERNESTO MICHELANGELO GIGLIO \\ UNIVERSIDADE PAULISTA}

\begin{abstract}
RESUMO
O campo de pesquisas em Redes na Administração não apresenta uma dominância paradigmática, sendo propício para discussões sobre afirmativas, modelos e teorias. O artigo analisa criticamente as contribuições das teses brasileiras sobre o tema de redes, na Administração, entre 2004 a 2013. Selecionaram-se critérios que definem contribuição, tanto da literatura nacional, quanto internacional, construindo-se um quadro com I2 indicadores sobre originalidade e oito sobre significância. A seleção das teses sobre redes resultou em 23 trabalhos. Realizaram-se duas formas de análise, uma com análise de conteúdo, nas partes que explicitam a contribuição e outra com a busca de expressões, conforme palavra chave de cada um dos 20 critérios. Como o campo de redes apresenta-se multifacetado nos seus conceitos, nas metodologias de investigação e nos modelos gerenciais, sendo propício para a discussão e desenvolvimento de novas abordagens; esperava-se encontrar contribuições nos três níveis. A análise revelou que a contribuição teórica é praticamente nula; que a contribuição metodológica é restrita, com esforços de melhorias metodológicas e que as contribuições gerenciais são as que mais aparecem, especialmente quando o autor analisa uma rede local. O resultado indica a necessidade de investigação e discussão mais aprofundada sobre o tema, por exemplo, com coordenadores e orientadores, considerando a situação paradigmática do campo.
\end{abstract}

Palavras-chave: teses; redes; contribuição; metodologia.

\section{ABSTRACT}

Research into Management Networks is not a dominant paradigm, which leaves it open for discussions on its statements, models and theories. This paper analyzes the contributions made by Brazilian theses on networks in the area of management, from 2004 to 2013 . For this purpose, criteria that define contribution are used, for both national and international literature, resulting in a chart of 12 originality and 8 significance indicators. 23 theses were identified as dealing with the subject of networks. Content analysis was employed on explicit contributing texts and a search of the keywords for each of the 20 indicators. As the subject of networks presents multifaceted concepts, research methodologies and management models, it is beneficial to discuss and develop new approaches and contributions were expected at all three levels. The results indicate, however, that theoretical contributions were practically non-existent, methodological contributions were limited, focusing on improvements, and managerial contributions were most common, especially when focused on local networks. The results and analysis show that more research and a deeper discussion on this subject are needed. These could include coordinators and supervisors due to the pre-paradigmatic nature of the topic.

Keywords: theses; networks; contribution; methodology. 


\section{INTRODUÇÃO}

$\mathrm{O}$ artigo analisa criticamente as contribuições das teses brasileiras sobre Redes, específicas do campo da Administração, no período de 2004 a 2013. Ocorre que o campo de Redes não apresenta uma dominância paradigmática clara, sendo aberto à discussão e contribuição teórica e metodológica, justificando, assim, o esforço de analisar se há uma linha, uma especificidade das contribuições das teses brasileiras sobre o conhecimento de redes. A análise pode indicar quais diretrizes teóricas e metodológicas estão se desenvolvendo e são mais utilizadas pelos orientadores e doutorandos brasileiros.

Como o tema de Redes é investigado em várias Ciências, optou-se por selecionar os trabalhos oriundos de Programas de Doutorado em Administração, que é a área de atuação dos autores. Em Administração existe labilidade no conceito de Redes; nas explicações sobre as origens dos grupos de negócios; sobre seus processos; na valorização de variáveis econômicas, racionais e sociais; nos critérios de resultados e até mesmo sobre a importância e lugar do fenômeno de redes, conforme afirmam alguns autores (GRANDORI, SODA, 1995; JONES; HESTERLY; BORGATTI, 1997; NOHRIA; ECLES, I992; POWELL; SMITH-DOER, I994; SACOMANO NETO, 2004; GIGLIO, 20Iо; WITTMANN; DOTTO; WEGNER, 20I3).

Considerando essa diversidade surge a pergunta sobre quais temas as teses brasileiras estariam investigando e contribuindo?

O trabalho se justifica porque o fenômeno de redes tornou-se importante e presente no circuito acadêmico, além da crescente necessidade de se compreender as ações coletivas para se criarem modelos gerenciais. No Brasil ainda são poucos os programas de Pós Graduação que buscam especialização no campo de Redes, com algumas ilhas de excelência no Sul do País, como a Federal do Rio Grande do Sul, a Unisinos e a Federal do Paraná; no Sudoeste, como a Federal de Lavras e a Universidade Paulista; e no Norte, como a Federal de Pernambuco. O ambiente organizacional atual de incertezas, imprevisibilidades e o incremento de grupos com ações cooperadas, sejam comerciais, de políticas públicas, de mercado solidário, 
ou de ações sociais de ajuda; ensejam esforços de se criarem afirmativas, modelos teorias e metodologias mais adaptadas à realidade brasileira.

Num campo assim caracterizado, com desenvolvimento em várias frentes, é importante conhecer as tendências epistêmicas, teóricas, metodológicas e aplicativas (MARTINS, 1994; CASTRO, 2002; THEÓPHILOS; IUDÍCIBUS, 2005).

Leituras prévias de algumas teses sobre Redes indicaram ausência de contribuições teóricas e metodológicas, quando se considera o critério de originalidade e significância, que é utilizado em universidades e revistas internacionais qualificadas. Alguns trabalhos classificados na área de Redes acabam por investigar empresas isoladas e, conforme Seleme e Orssato (1990), tais análises não contribuem para o conhecimento sobre Redes. Com base nessas evidências iniciais sobre a possível dificuldade das teses brasileiras em contribuir cientificamente, propõe-se neste artigo verificar as promessas e os resultados de teses sobre Redes, considerando a produção do período de 2004 a 2013.

A ideia convergente sobre o critério do que é contribuição de uma tese refere-se à situação em que um pesquisador parte de um ponto do conhecimento teórico, ou metodológico, e, ao final, apresenta uma inovação, ou um complemento que leva o conhecimento além do ponto de partida. Assim, o próximo pesquisador inicia um passo adiante do que existia antes da tese. Essa linha de compreensão sobre o que é contribuição é defendida por autores nacionais (CASTRO, I978; ASTI-VERA, I980; BERTERO; CALDAS; WOOD, I999; MARQUES, 2000; WETTEN, 2003) e encontra convergência nos parâmetros definidos por algumas universidades americanas e europeias.

O artigo está estruturado da seguinte forma: esta introdução, onde se coloca o tema, o problema, a justificativa e o benefício esperado; referencial sobre as linhas dominantes de teorias sobre redes, aceitando-se que elas determinam as trilhas de pesquisa no mundo acadêmico; metodologia, apresentando os critérios de contribuição e a forma de análise das teses; apresentação e discussão dos resultados e considerações finais. 


\section{AS ABORDAGENS SOBRE REDES E AS TEMÁTICAS DOMINANTES}

Neste item apresentam-se as perspectivas explicativas dominantes sobre o fenômeno de redes, as quais influenciam as trilhas de pesquisa no mundo acadêmico. Realizou-se uma busca de artigos que analisaram a produção e os paradigmas em redes, encontrando-se as convergências.

Existem exemplos mais frequentemente referenciados na literatura internacional sobre o esforço de reunir as contribuições sobre Redes. Tichy, Tushmam e Fombrun (1979) classificaram os estudos de Redes nos temas dos fluxos, da natureza dos laços e nas características estruturais. Os autores afirmaram que estudos estanques (de recursos em máquinas e equipamentos, por exemplo) não podem contribuir para a compreensão das redes. Miles e Snow (1986) afirmaram que a estrutura em rede é a forma dominante de relações entre organizações. Nohria e Ecles (1992) reuniram o estado da arte de duas décadas sobre o tema de Redes, afirmando que toda organização está em rede, mesmo que seus participantes não utilizem suas conexões. Grandori e Soda (1995) afirmaram a governança como a essência dos processos de redes. Larson (1993) buscou caracterizar o processo de desenvolvimento das redes, colocando no primeiro passo as variáveis de recursos e secundariamente as variáveis sociais. Autores brasileiros (SACOMANO NETO, 2004; GIGLIO, 20I0; WEGNER; PADULA, 2013) também analisaram as convergências e o leque de perspectivas sobre Redes.

Os trabalhos indicam que existem cinco grandes abordagens sobre Redes, que abarcam um amplo leque de afirmativas, modelos, teorias e metodologias. O Quadro I apresenta o resumo criado com base nas afirmativas convergentes sobre essas abordagens e as linhas de pesquisa que elas originam.

Como se verifica, são cinco perspectivas, cada uma delas contando com teorias de apoio e com modelos e afirmativas que se reproduzem nos meios científicos. A soma dessa variedade de explicações com a atualidade e multiplicidade de manifestações do fenômeno de redes (de negócios, de cooperação, de políticas públicas, de ajuda social, de consumidores, entre outras) resulta num campo propício de criação de novas vertentes explicativas. 
Quando um campo de conhecimento, como é o caso de Redes, encontrase numa situação de não domínio de um paradigma (KUHN, 1970), há maior liberdade de criação e expressão e, por inferência, as teses apresentariam contribuições para o conhecimento da área.

Quadro I Os pontos de partida das principais abordagens sobre redes

\begin{tabular}{|c|c|c|c|c|c|}
\hline $\begin{array}{l}\text { Paradigma } \rightarrow \\
\text { Categoria } \downarrow\end{array}$ & $\begin{array}{l}\text { Racional e } \\
\text { Econômico }\end{array}$ & Social-Técnico & $\begin{array}{l}\text { Sociedade em } \\
\text { Rede }\end{array}$ & Estrutura & Governança \\
\hline $\begin{array}{l}\text { Afirmativa } \\
\text { básica sobre } \\
\text { redes }\end{array}$ & $\begin{array}{l}\text { A rede se forma } \\
\text { por motivos e } \\
\text { objetivos de } \\
\text { dependência } \\
\text { de recursos e } \\
\text { econômicos. }\end{array}$ & $\begin{array}{l}\text { A rede se forma e } \\
\text { se desenvolve com } \\
\text { base nas relações } \\
\text { sociais; cada ator } \\
\text { está imerso e } \\
\text { comprometido na } \\
\text { rede. }\end{array}$ & $\begin{array}{l}\text { Todas as } \\
\text { organizações } \\
\text { estão em rede, } \\
\text { quer utilizem, } \\
\text { ou não, suas } \\
\text { conexões. }\end{array}$ & $\begin{array}{l}\text { Conjunto } \\
\text { de nós, que } \\
\text { podem ser } \\
\text { mensurados. }\end{array}$ & $\begin{array}{l}\text { São arranjos } \\
\text { planejados para } \\
\text { se resolver a } \\
\text { interdependência } \\
\text { de recursos. }\end{array}$ \\
\hline $\begin{array}{l}\text { Exemplos } \\
\text { de teorias, } \\
\text { modelos, } \\
\text { afirmativas e } \\
\text { autores mais } \\
\text { referenciados }\end{array}$ & $\begin{array}{l}\text { Custos de } \\
\text { Transação } \\
\text { (Williamson, } \\
\text { 1981). } \\
\text { Racionalidade } \\
\text { de Escolhas } \\
\text { (Clemen,1996). } \\
\text { Teoria dos } \\
\text { Jogos (Axelrod, } \\
\text { 1986). }\end{array}$ & $\begin{array}{l}\text { Dinâmica de } \\
\text { pequenos grupos } \\
\text { (Golembiewski, } \\
\text { 1962). } \\
\text { Teoria da } \\
\text { Comunicação } \\
\text { (Bitti; Zani,1993). } \\
\text { Embeddedness } \\
\text { (Polanyi; } \\
\text { Arensberg; } \\
\text { Pearson, 1957; } \\
\text { Granovetter,1985) }\end{array}$ & $\begin{array}{l}\text { Sociologia de } \\
\text { grandes grupos } \\
\text { (Castells, 2000). } \\
\text { Teoria da } \\
\text { Comunicação } \\
\text { (Bitti; Zani,1993). } \\
\text { Ecologia } \\
\text { (Maturana; Varela, } \\
\text { 1995). } \\
\text { Teoria do Rizoma } \\
\text { (Deleuze; } \\
\text { Guattari, 2000) }\end{array}$ & $\begin{array}{l}\text { Teorias dos } \\
\text { grafos (Gross; } \\
\text { Yellen, 2004) } \\
\text { Análise } \\
\text { estrutural das } \\
\text { redes (Burt, } \\
\text { 1976) }\end{array}$ & $\begin{array}{l}\text { Modelos de } \\
\text { governança } \\
\text { (Jones; Hesterly; } \\
\text { Borgatti, 1997; } \\
\text { (Provan, 1993) }\end{array}$ \\
\hline $\begin{array}{l}\text { Objeto de } \\
\text { estudo mais } \\
\text { frequente }\end{array}$ & $\begin{array}{l}\text { As variações } \\
\text { econômicas e } \\
\text { de recursos na } \\
\text { rede. }\end{array}$ & $\begin{array}{l}\text { As relações sociais } \\
\text { na rede. }\end{array}$ & $\begin{array}{l}\text { O fluxo entre os } \\
\text { atores da rede. }\end{array}$ & $\begin{array}{l}\text { Estrutura } \\
\text { dos nós. } \\
\text { Determinação } \\
\text { da força dos } \\
\text { laços. }\end{array}$ & $\begin{array}{l}\text { As formas de } \\
\text { controle e } \\
\text { incentivo das } \\
\text { ações coletivas. }\end{array}$ \\
\hline $\begin{array}{l}\text { Objetivos } \\
\text { de pesquisa } \\
\text { mais } \\
\text { frequentes }\end{array}$ & $\begin{array}{l}\text { Relacionar } \\
\text { a variável } \\
\text { econômica e de } \\
\text { recursos com } \\
\text { outras variáveis, } \\
\text { tais como } \\
\text { inovação e } \\
\text { aprendizagem. }\end{array}$ & $\begin{array}{l}\text { Verificar como } \\
\text { temas sociais } \\
\text { específicos, como } \\
\text { confiança, afetam } \\
\text { a estrutura e } \\
\text { dinâmica das } \\
\text { redes. }\end{array}$ & $\begin{array}{l}\text { Descrever } \\
\text { processos de } \\
\text { fluxos sociais } \\
\text { e econômicos } \\
\text { de redes em } \\
\text { qualquer estado, } \\
\text { ou estágio de } \\
\text { desenvolvimento }\end{array}$ & $\begin{array}{l}\text { Criar desenhos } \\
\text { da estrutura } \\
\text { dos laços } \\
\text { fortes. }\end{array}$ & $\begin{array}{l}\text { Verificar e } \\
\text { analisar os } \\
\text { processos de } \\
\text { solução de } \\
\text { conflitos e } \\
\text { incentivos para } \\
\text { ações coletivas. }\end{array}$ \\
\hline
\end{tabular}




\begin{tabular}{|c|c|c|c|c|c|}
\hline $\begin{array}{l}\text { Paradigma } \rightarrow \\
\text { Categoria } \downarrow\end{array}$ & $\begin{array}{l}\text { Racional e } \\
\text { Econômico }\end{array}$ & Social-Técnico & $\begin{array}{l}\text { Sociedade em } \\
\text { Rede }\end{array}$ & Estrutura & Governança \\
\hline $\begin{array}{l}\text { Linha } \\
\text { geral das } \\
\text { conclusões }\end{array}$ & $\begin{array}{l}\text { Discutir as } \\
\text { leis que } \\
\text { determinam } \\
\text { as relações } \\
\text { entre variáveis } \\
\text { econômicas } \\
\text { e outras, } \\
\text { tais como } \\
\text { número de } \\
\text { participantes. }\end{array}$ & $\begin{array}{l}\text { Discutir e defender } \\
\text { a importância da } \\
\text { questão social } \\
\text { nas relações } \\
\text { comerciais, } \\
\text { tais como o } \\
\text { comprometimento }\end{array}$ & $\begin{array}{l}\text { Descrever o } \\
\text { estado de } \\
\text { organização e } \\
\text { desenvolvimento } \\
\text { de redes; } \\
\text { considerando } \\
\text { desde estados } \\
\text { latentes, } \\
\text { até redes } \\
\text { formalmente } \\
\text { existentes. }\end{array}$ & $\begin{array}{l}\text { Descrever a } \\
\text { posição dos } \\
\text { atores e criar } \\
\text { inferências } \\
\text { sobre poder, } \\
\text { hierarquia, } \\
\text { liderança, } \\
\text { entre outros. }\end{array}$ & $\begin{array}{l}\text { Inferir processos } \\
\text { e sugerir } \\
\text { ações de } \\
\text { fortalecimento } \\
\text { dos laços. }\end{array}$ \\
\hline
\end{tabular}

Desta situação surgem algumas perguntas: (a) Estariam os programas de doutorado do Brasil seguindo alguma perspectiva específica? (b) Existem temas mais recorrentes nas teses? (c) Existem regiões, ou universidades específicas que marcam suas teses com uma identidade?

O artigo levanta a seguinte pergunta orientadora e alguns desdobramentos: (a) As teses brasileiras estão apresentando contribuições? (b) Qual a natureza dessas contribuições? (c) Seguiriam abordagens mais racionais e econômicas, como é o caso de algumas escolas americanas? (d) Seguiriam mais as abordagens sociais advindas dos estudos de clusters e de policy networks da Europa? (e) Teriam uma vertente metodológica, aproximando-se dos esforços de grupos, como os finlandeses (HALINEN; SALMI; HAVILA, I999), ou da escola alemã, sobre governança (JONES; HESTERLY; BORGATTI, I997)?

A pergunta específica sobre a contribuição sugere os seguintes questionamentos: (a) Em caso de se encontrarem contribuições, há uma convergência entre elas? (b) As temáticas voltam-se mais para contribuições teóricas, metodológicas, ou gerenciais? (c) Existe alguma linha definida conforme a origem da instituição das teses?

Em função desses questionamentos desenvolveu-se o plano da pesquisa. 


\section{METODOLOGIA}

A primeira tarefa da pesquisa consistiu em definir operacionalmente a expressão contribuição. Buscaram-se textos nos programas de pós-graduação de universidades; nos artigos de revistas científicas; e nas instituições de controle e incentivo da pós-graduação; encontrando-se uma linha internacional bem definida sobre o que é uma contribuição e uma linha brasileira mais flexível.

\section{A CONTRIBUIÇÃO DE UMA TESE CONFORME MODELOS INTERNACIONAIS}

Nas universidades britânicas, segundo orientação da British Academy Regulation 2.5, a orientação formal dada pelos regulamentos das Universidades, sobre o que é exigido de uma tese de doutorado (PhD) é que ela deve conter "uma contribuição original para o conhecimento, ou entendimento" (UNIVERSITY OF YORK, 20II). Para a maioria dos campos de pesquisa, isto significa que a tese deve apresentar pelo menos uma das três condições:

a. Adicionar conhecimento teórico ao já existente;

b. Desenvolver uma nova abordagem de algum fenômeno empírico, ou na área de conhecimento;

c. Defender de forma convincente a interpretação do conhecimento teórico, ou aplicado em um campo do conhecimento.

A Universidade de Ottawa, no Canadá, em seu guia (UNIVERSITY OF OTAWA, 2004) coloca que, dentro do possível, a tese deve ser uma contribuição original e significativa (no sentido de atual e importante), incorporando os resultados da investigação original, e ter qualidade meritória para ser publicada.

A orientação das Universidades da Austrália quanto a teses de doutorado é convergente com as anteriores. A Monash University (20I3) recomenda à banca examinadora três importantes diretrizes:

I Que a tese seja uma contribuição significativa ao conhecimento e ao entendimento no campo de estudo;

II Que a tese possa ser publicada;

III Que o formato e a grafia estejam satisfatórios. 
A Charles Sturt University (2013) orienta que os candidatos devem ter avançado conhecimento teórico e metodológico, e devem trazer uma contribuição original e significativa ao conhecimento.

Nos Estados Unidos, a Universidade de Yale utiliza como referência o trabalho de Lovitts e Bert (2009) resultado de uma pesquisa com docentes, que trata sobre o desenvolvimento de teses de qualidade. As respostas estabeleceram um entendimento dos termos originalidade e significância que os professores utilizam constantemente quando se trata de teses. Segundo a Universidade de Yale, embora seja um trabalho voltado para as Ciências Sociais, pode ser utilizado em outras áreas do conhecimento. A originalidade da contribuição está presente quando o trabalho oferece uma nova perspectiva, e é descrita como algo que não foi feito, encontrado, ou visto antes. É publicável porque acrescenta conhecimento; muda a forma como as pessoas pensam; oferece diretrizes; move o campo do conhecimento para frente; avança o estado da arte. Isso pode ser obtido ao se desenvolver uma visão original do conhecimento, ou um avanço dele, ou utilizar uma contribuição de outro campo da ciência e aplicá-la no seu campo pela primeira vez.

Quanto à significância da contribuição, Lovitts e Bert (2009) descreveram como algo que é útil e vai ter um impacto, e por isso é publicável em revistas de primeira linha.

Para Umberto Eco (2008) uma tese de doutorado deve ser representada por uma pesquisa original, por meio do conhecimento profundo do que já foi escrito sobre o mesmo argumento pela literatura e, sobretudo, por desvelar algo que não foi abordado por outros estudiosos.

Whetten (2003) apresentou os sete fatores mais relevantes na avaliação de artigos conceituais (artigos teóricos) onde destaca que originalidade não é necessariamente gerar novas teorias, mas novas modificações, ou extensões de teorias atuais com impacto importante no conhecimento existente.

A convergência das afirmativas é que a tese deve ser original, no sentido de apresentar algo antes inexistente, mesmo que seja uma extensão de algo já existente, mas numa perspectiva não investigada. 
Sobre significância, apesar de alguma convergência no sentido de ter impacto e ser atual, observa-se uma margem de percepção do avaliador, sobre possíveis impactos e usos do trabalho.

\section{A CONTRIBUIÇÃO DE UMA TESE CONFORME MODELOS BRASILEIROS}

No Brasil o entendimento de contribuição de uma tese de doutorado é diversamente descrito pelos programas de pós-graduação, com certo grau de liberdade com base no parecer do Conselho de Educação Superior (CES) e das normas ABNT.

O parecer CES/CFE 977/65 coloca que uma tese deve ser elaborada com base em investigação original, devendo representar trabalho de real contribuição para o tema escolhido, ou seja, original é definido como algo que não existia antes (SUCUPIRA, 1965). A ABNT, na NBR-I4724 (ABNT, 2005), caracteriza uma tese de doutorado, como um trabalho de tema único, bem definido e delimitado, constituindo uma real contribuição, sob a orientação de um coordenador. Neste caso fica aberta a possibilidade do orientador definir o que é original.

Prodanov (2013) afirma que a originalidade de uma tese não precisa ser necessariamente algo novo, ou nunca estudado; podendo ser a reinterpretação (portanto, considerada inédita) de algo já estudado e que permite um avanço de conhecimentos naquele campo. O mesmo é afirmado por Marques (2000), sobre a originalidade não ser exclusivamente algo novo, mas também uma nova expressão de algo já escrito e analisado. Uma volta às origens, por exemplo, seria algo original.

$\mathrm{Na}$ defesa da labilidade do conceito de originalidade, Salomon (1972) argumenta que a originalidade como total novidade em uma tese de doutorado é uma exigência ingênua, para não dizer inatingível, por três motivos:

a. Porque a ciência é um processo cumulativo e a revisão é uma constante;

b. Porque mais do que originalidade, trata-se da relevância contemporânea na escolha do problema a ser investigado;

c. Porque, historicamente, original pode ser um modo novo de abordar 
um assunto já tratado, ou que traga novas relações, ou, ainda, uma visão diferente na interpretação de questões controversas.

De acordo com Castro (1978), uma tese deve atender três pontos: originalidade, importância e viabilidade. A originalidade não precisa estar associada ao que nunca foi feito, mas relacionada com o potencial de surpreender. A importância surge quando o tema polariza, ou impacta um segmento da sociedade. Desta maneira a tese deve:

I Estar relacionada a uma questão que mereça atenção (critério de importância);

II Possibilitar novos entendimentos em relação aos fenômenos observados (critério de originalidade);

III Ser passível de observação em relação ao aparato teórico e técnico, às condições de prazo, custo e competências dos pesquisadores (critério de viabilidade).

Outros autores afirmaram variações sobre os indicadores da contribuição. Para Severino (2007) a tese deve trazer uma contribuição nova relativa ao tema abordado. Para Martins (2002) quando os indicadores mostram que os resultados podem surpreender há sinais de originalidade. Para Asti-Vera (I980) originalidade é o retorno à origem, essência e verdade; e não pode ser confundida com novidade, ou singularidade. Desta maneira, a originalidade ocorre pela abordagem dada ao assunto, na definição dos seus limites, ou da metodologia utilizada.

Castro (1978) e Bertero, Caldas e Wood (1999) sugerem critérios para a análise da produção científica nacional de artigos, extensivo às teses:

a. Coerência relacionada à teorização e sustentação consistente do argumento principal;

b. Originalidade e inovação, relacionadas ao ineditismo do argumento, da teoria e das conclusões;

c. Nível de surpresa relacionado ao impacto produzido pelo argumento;

d. Contribuição para a ciência e de utilidade para pesquisa futura relacionada ao avanço do conhecimento. 
Como se verifica, existem algumas convergências e diferenças sobre os indicadores afirmados por autores e fontes brasileiras, e uma convergência que a distingue das fontes internacionais, sobre a originalidade não ser necessariamente algo que não existia antes.

Fontes brasileiras e internacionais concordam em dois pontos: a tese precisa ter originalidade e significância. Divergem, no entanto, sobre o que é originalidade e significância. As afirmativas internacionais são mais categóricas em afirmar que a originalidade é algo novo, inexistente até o momento, seja uma teoria, ou um aspecto metodológico. Já as afirmativas brasileiras colocam a originalidade não só como algo novo, mas também como soma ao que já existe.

Para os propósitos exploratórios deste trabalho decidiu-se manter os indicadores nacionais e internacionais, por isso o Quadro 2 foi construído para preservar a origem do indicador (se nacional, ou internacional) e sua classificação dentro das duas categorias (se originalidade, ou significância).

As frases colocadas em cada indicador foram extraídas diretamente dos textos encontrados e ao final de cada uma colocou-se a palavra chave, que foi utilizada como um dos critérios de busca e análise das teses selecionadas. Os critérios encontrados no item D, das universidades brasileiras (USP, 2008; UFV, 2010; UFLA, 2010; UFMG, 2013) apresentam o mesmo conteúdo de outros indicadores, por isso são apresentados, mas não utilizados nas análises, já que se encontram nos itens A, B e C.

Quadro 2 Operacionalização do conceito de Contribuição das teses, desdobrada em Originalidade e Significância

\begin{tabular}{|c|c|c|}
\hline & Sinais de Originalidade & Sinais de Significância \\
\hline $\begin{array}{l}\text { A. Associações } \\
\text { e Instituições } \\
\text { Reguladoras } \\
\text { brasileiras e } \\
\text { internacionais. }\end{array}$ & $\begin{array}{l}\text { A.1. Tema único, ainda inexistente na } \\
\text { literatura. } \\
\text { (ÚNICO) } \\
\text { A.2. Contribuição claramente delimitada } \\
\text { a um tópico da Administração. } \\
\text { (DELIMITAÇÃO, ESCOPO) } \\
\text { A.3. Produzido pela primeira vez. } \\
\text { (ORIGINAL, PRIMEIRA VEZ) } \\
\text { A.4. Não segue e nem repete modelo já } \\
\text { existente. } \\
\text { (MODELO NOVO) }\end{array}$ & \\
\hline
\end{tabular}




\begin{tabular}{|c|c|c|}
\hline & Sinais de Originalidade & Sinais de Significância \\
\hline $\begin{array}{l}\text { B. Universidades } \\
\text { internacionais }\end{array}$ & $\begin{array}{l}\text { B.1. Adiciona conhecimento teórico. A } \\
\text { adição está claramente expressa no } \\
\text { texto do autor. } \\
\text { (TEÓRICO + AVANÇO, OU ADIÇÃO) } \\
\text { B.2. Desenvolve uma nova abordagem, } \\
\text { no sentido de metodologia de } \\
\text { investigação. } \\
\text { (NOVA + METODOLOGIA) } \\
\text { B.3. Defende a interpretação de um } \\
\text { fenômeno, quando tal interpretação } \\
\text { ainda está em desenvolvimento e } \\
\text { aceitação na comunidade científica. } \\
\text { (DEFESA + TEORIA) } \\
\text { B.4. Refere-se a algo que não foi } \\
\text { feito, encontrado, ou visto antes, } \\
\text { principalmente em metodologia de } \\
\text { pesquisa. } \\
\text { (NOVIDADE, NOVO, MÉTODO) } \\
\text { B.5. Utiliza conhecimento de outra área } \\
\text { científica pela primeira vez. } \\
\text { (AREA+CIENTíFICA) }\end{array}$ & $\begin{array}{l}\text { B.6 Muda a forma como as } \\
\text { pessoas pensam e interpretam } \\
\text { certos fenômenos. } \\
\text { (MUDANÇA + PENSAR) } \\
\text { B.7. Dá diretrizes para } \\
\text { desenvolver pesquisas e criar } \\
\text { novos modelos. } \\
\text { (RUMO, DIRETRIZES, TRILHA + } \\
\text { PESQUISA) }\end{array}$ \\
\hline $\begin{array}{l}\text { C. Autores } \\
\text { internacionais }\end{array}$ & & $\begin{array}{l}\text { C.1. Tem utilidade, no sentido de } \\
\text { aplicação e gerência. } \\
\text { (APLICAÇÃO, APLICABILIDADE) } \\
\text { C.2. Pode ser publicada, isto é, } \\
\text { tem importância suficiente para } \\
\text { ser apresentada à comunidade } \\
\text { científica. } \\
\text { (IMPORTÂNCIA) }\end{array}$ \\
\hline $\begin{array}{l}{ }^{*} \text { D. Universidades } \\
\text { brasileiras }\end{array}$ & $\begin{array}{l}\text { D.1 Tema único, bem delimitado, } \\
\text { investigação original. (=A1, A2) } \\
\text { D.2 Originalidade no tratamento do } \\
\text { tema (=B2) }\end{array}$ & $\begin{array}{l}\text { D.3. Trazer contribuições para a } \\
\text { teoria e práticas administrativas } \\
\text { (=C1). }\end{array}$ \\
\hline
\end{tabular}




\begin{tabular}{|c|c|c|}
\hline & Sinais de Originalidade & Sinais de Significância \\
\hline E. Autores brasileiros & $\begin{array}{l}\text { E.1. Revelar algo que estava oculto até } \\
\text { aquele momento. } \\
\text { (REVELAR, DESVELAR) } \\
\text { E.2. Afirmar o mesmo com base em outro } \\
\text { ângulo, ou seja, utilizando outra teoria, } \\
\text { não dominante até aquele momento. } \\
\text { (REINTERPRETAR, REVISAR, REORDENAR) } \\
\text { E.3. Voltar à essência do fenômeno, } \\
\text { no sentido de resgatar significados } \\
\text { e eventos que ficaram ocultos por } \\
\text { paradigmas dominantes. } \\
\text { (RECUPERAR, REVIVER, RETORNAR) }\end{array}$ & $\begin{array}{l}\text { E.4. Relevância atual do tema, } \\
\text { conforme acontecimentos } \\
\text { contemporâneos. } \\
\text { (ATUAL, RELEVANTE, } \\
\text { CONTEMPORÂNEO) } \\
\text { E.5. Mostra operacionalidade, } \\
\text { com conceitos e planos de } \\
\text { pesquisa possíveis de serem } \\
\text { realizados e repetidos. } \\
\text { (OPERACIONALIDADE) } \\
\text { E.6. Nível de surpresa do impacto } \\
\text { produzido pelo argumento, no } \\
\text { sentido de um ângulo novo, } \\
\text { criativo, inventivo, crítico. } \\
\text { (IMPACTO, SURPRESA) } \\
\text { E.7. Cria interesse e novos } \\
\text { campos de investigação para os } \\
\text { pesquisadores. } \\
\text { (INTERESSE, TRILHAS, PESQUISAS, } \\
\text { NOVAS) }\end{array}$ \\
\hline
\end{tabular}

* Como os critérios são os mesmos encontrados em A e em C, não foram utilizados nas análises.

O Quadro 2 indica que as fontes internacionais convergem na ideia de originalidade como algo anteriormente inexistente, ao passo que as fontes brasileiras colocam uma amplitude maior na originalidade, aceitando que o original pode ser algo já escrito, mas não bem defendido; ou algo já investigado, adicionando-se um elemento explicativo, ou o retorno à essência, recuperando significados antigos.

Já a operacionalização de significância não foi claramente estabelecida, variando entre critérios que podem ser objetivos (como a quantidade de novos temas emergentes na nova perspectiva), até critérios subjetivos e perceptuais (como a avaliação de surpresa que o trabalho apresenta).

Diante dessa circunstância de diferença entre critérios de originalidade e certa subjetividade da significância, decidiu-se manter todos os indicadores encontrados, que serão utilizados como um quadro referencial inicial, até como forma de investigar quais deles mostram-se mais operacionais e competentes na análise de teses. 


\section{SELEÇÃO DAS TESES}

Para buscar e selecionar as teses cruzaram-se os bancos de dados da Capes, do IBCT- Biblioteca Digital de Teses Brasileiras e da Scielo, restringindose à última década. Como palavra de busca no título colocou-se Redes. No banco da Capes obteve-se 169 resultados, que filtrados por áreas de conhecimento correlatas resulta em 57. A leitura dos resumos desses 57 trabalhos indicou que alguns se originam de outras áreas do conhecimento, como Matemática, Informática e Neurociências, apesar do banco de dados informar como correlatas. Como a proposta é investigar trabalhos da Administração, realizando a exclusão chegou-se a I4 teses. O banco de dados da Capes traz resultados desde 20II. A expressão Redes retorna 362 indicações, mantendo-se os filtros de dez anos (2004 a 2013) e teses nacionais. Pela limitação dos filtros, optou-se pela análise individual, chegando-se ao número de 25 teses, eliminando-se as redundâncias trazidas pelos dois bancos de busca. Destas 25, duas foram desqualificadas, durante a análise de contribuição, por serem teses não relacionadas a Redes, embora atendessem as premissas de seleção, obtendo-se 23 teses.

Para cada tese realizaram-se duas formas de análise:

a. Análise das frases sobre as contribuições do trabalho, principalmente na leitura do resumo, da introdução e de itens específicos sobre objetivos e benefícios do trabalho. A conclusão de cada análise seguiu os preceitos da análise temática (BARDIN, 1977), considerando o ponto principal dos parágrafos;

b. Busca de frases contendo a palavra chave de cada indicador. Esta análise permite encontrar informações sobre as contribuições do trabalho, mesmo que não estejam nas partes investigadas pela análise anterior. 


\section{APRESENTAÇÃO E ANÁLISE DOS DADOS}

Na primeira organização dos dados colocaram-se as universidades participantes e as teses distribuídas ano a ano. Conforme se verifica na Tabela I, as universidades do Rio Grande do Sul, especialmente a UFRGS, com I4 teses, dominam a produção nacional de teses sobre Redes, seguidas de São Paulo, com seis teses. Um dos motivos dessa dominância é resultado do programa de desenvolvimento de redes de pequenas empresas, implantado há alguns anos atrás, pelo governo estadual.

Tabela I Distribuição das teses brasileiras do período de 2004 a 2013 conforme a universidade de origem

\begin{tabular}{|lll|}
\hline Ano & Universidade & Total \\
\hline 2004 & UFRGS; FGVSP & 2 \\
\hline 2005 & 2 UFRGS; 1 UFBA & 3 \\
\hline 2006 & UFRGS & 2 \\
\hline 2007 & & 0 \\
\hline 2008 & UFRGS & 1 \\
\hline 2009 & 3 USP; 1 UFRGS; 1 MACKENZIE & 5 \\
\hline 2010 & 3 UFRGS; 1 USP & 4 \\
\hline 2011 & 1 UFRGS; 1 UnB; 1 UNISINOS; 1 FGVSP & 4 \\
\hline 2012 & 1 UFRGS; 1 UNISINOS & 2 \\
\hline 2013 & & 0 \\
\hline Total & & $\mathbf{2 3}$ \\
\hline
\end{tabular}

A segunda organização dos dados é a apresentação das 23 teses, uma a uma, conforme a presença, ou ausência dos 20 indicadores, com os resultados apresentados no Quadro 3. As letras com números (AI, A2,...) referem-se aos indicadores mostrados no Quadro 2. A letra AC significa análise de conteúdo (a primeira forma de análise) e a letra $\mathrm{CH}$ significa chave, a segunda forma de análise realizada. Em cada célula está colocada a letra $S$ (para presença constatada do indicador), ou a letra $\mathrm{N}$ (para indicador não encontrado), sendo o numerador o resultado da $\mathrm{AC}$ e o denominador o resultado da $\mathrm{CH}$. Por exemplo, na tese $2004 \mathrm{~A}$, na primeira célula, o resultado N/N significa 
que aquele indicador (no caso o indicador Ar, que é sobre tema único, não existente na literatura) não está presente nas duas formas de análises.

Quadro 3 Análise das contribuições apresentadas pelas teses brasileiras no período de io anos, conforme indicadores de originalidade levantados na literatura

\begin{tabular}{|c|c|c|c|c|c|c|c|c|c|c|c|c|}
\hline \multirow[t]{2}{*}{ Tese } & \multicolumn{12}{|c|}{ Indicadores de Originalidade. $\mathrm{AC}=$ Análise de Conteúdo; $\mathrm{CH}=$ Palavra chave encontrada } \\
\hline & A1 & A2 & A3 & A4 & B1 & B2 & B3 & B4 & B5 & E1 & E2 & E3 \\
\hline & $\mathrm{AC} / \mathrm{CH}$ & $\mathrm{AC} / \mathrm{CH}$ & $\mathrm{AC} / \mathrm{CH}$ & $\mathrm{AC} / \mathrm{CH}$ & $\mathrm{AC} / \mathrm{CH}$ & $\mathrm{AC} / \mathrm{CH}$ & $\mathrm{AC} / \mathrm{CH}$ & $\mathrm{AC} / \mathrm{CH}$ & $\mathrm{AC} / \mathrm{CH}$ & $\mathrm{AC} / \mathrm{CH}$ & $\mathrm{AC} / \mathrm{CH}$ & $\mathrm{AC} / \mathrm{CH}$ \\
\hline $2004 A$ & $\mathrm{~N} / \mathrm{N}$ & $\mathrm{N} / \mathrm{S}$ & $\mathrm{N} / \mathrm{N}$ & $\mathrm{N} / \mathrm{N}$ & $\mathrm{N} / \mathrm{S}$ & $\mathrm{N} / \mathrm{N}$ & $\mathrm{N} / \mathrm{N}$ & $\mathrm{N} / \mathrm{S}$ & $\mathrm{N} / \mathrm{N}$ & $\mathrm{N} / \mathrm{N}$ & $\mathrm{N} / \mathrm{N}$ & $\mathrm{N} / \mathrm{N}$ \\
\hline 2004B & $\mathrm{N} / \mathrm{N}$ & $\mathrm{N} / \mathrm{S}$ & $\mathrm{N} / \mathrm{N}$ & $\mathrm{N} / \mathrm{N}$ & $\mathrm{N} / \mathrm{N}$ & $\mathrm{N} / \mathrm{N}$ & $\mathrm{N} / \mathrm{N}$ & $\mathrm{N} / \mathrm{N}$ & $\mathrm{N} / \mathrm{N}$ & $\mathrm{N} / \mathrm{N}$ & $\mathrm{N} / \mathrm{N}$ & $\mathrm{N} / \mathrm{N}$ \\
\hline $2005 A$ & $\mathrm{~N} / \mathrm{N}$ & $\mathrm{N} / \mathrm{N}$ & $\mathrm{N} / \mathrm{N}$ & $\mathrm{N} / \mathrm{N}$ & $\mathrm{N} / \mathrm{N}$ & $\mathrm{N} / \mathrm{N}$ & $\mathrm{N} / \mathrm{N}$ & $\mathrm{N} / \mathrm{N}$ & $\mathrm{N} / \mathrm{N}$ & $\mathrm{N} / \mathrm{N}$ & $\mathrm{N} / \mathrm{N}$ & $\mathrm{N} / \mathrm{N}$ \\
\hline 2005B & $\mathrm{N} / \mathrm{N}$ & $\mathrm{N} / \mathrm{S}$ & $\mathrm{N} / \mathrm{N}$ & $\mathrm{N} / \mathrm{N}$ & $\mathrm{N} / \mathrm{N}$ & $\mathrm{N} / \mathrm{N}$ & $\mathrm{N} / \mathrm{N}$ & $\mathrm{N} / \mathrm{N}$ & $\mathrm{N} / \mathrm{N}$ & $\mathrm{N} / \mathrm{N}$ & $\mathrm{N} / \mathrm{N}$ & $\mathrm{N} / \mathrm{N}$ \\
\hline $2005 C$ & $\mathrm{~N} / \mathrm{N}$ & $\mathrm{N} / \mathrm{N}$ & $\mathrm{N} / \mathrm{N}$ & $\mathrm{N} / \mathrm{N}$ & $\mathrm{N} / \mathrm{S}$ & $\mathrm{N} / \mathrm{N}$ & $\mathrm{N} / \mathrm{N}$ & $\mathrm{N} / \mathrm{N}$ & $\mathrm{N} / \mathrm{N}$ & $\mathrm{N} / \mathrm{N}$ & $\mathrm{N} / \mathrm{N}$ & $\mathrm{N} / \mathrm{N}$ \\
\hline $2006 \mathrm{~A}$ & $\mathrm{~N} / \mathrm{N}$ & $S / S$ & $\mathrm{~N} / \mathrm{N}$ & $S / S$ & $\mathrm{~N} / \mathrm{N}$ & $\mathrm{N} / \mathrm{N}$ & $\mathrm{N} / \mathrm{N}$ & $\mathrm{N} / \mathrm{S}$ & $\mathrm{N} / \mathrm{N}$ & $\mathrm{N} / \mathrm{N}$ & $\mathrm{N} / \mathrm{N}$ & $\mathrm{N} / \mathrm{N}$ \\
\hline 2006B & $\mathrm{N} / \mathrm{N}$ & $\mathrm{N} / \mathrm{N}$ & $\mathrm{N} / \mathrm{N}$ & $S / S$ & $S / S$ & $\mathrm{~N} / \mathrm{S}$ & $\mathrm{N} / \mathrm{N}$ & $\mathrm{N} / \mathrm{S}$ & $\mathrm{N} / \mathrm{N}$ & $\mathrm{N} / \mathrm{N}$ & $\mathrm{N} / \mathrm{N}$ & $\mathrm{N} / \mathrm{N}$ \\
\hline $2008 A$ & $\mathrm{~N} / \mathrm{N}$ & $\mathrm{N} / \mathrm{N}$ & $\mathrm{N} / \mathrm{N}$ & $\mathrm{N} / \mathrm{N}$ & $\mathrm{N} / \mathrm{N}$ & $\mathrm{N} / \mathrm{N}$ & $\mathrm{N} / \mathrm{N}$ & $\mathrm{N} / \mathrm{N}$ & $\mathrm{N} / \mathrm{N}$ & $\mathrm{N} / \mathrm{N}$ & $\mathrm{N} / \mathrm{N}$ & $\mathrm{N} / \mathrm{N}$ \\
\hline $2009 A$ & $\mathrm{~N} / \mathrm{N}$ & $\mathrm{N} / \mathrm{N}$ & $\mathrm{N} / \mathrm{N}$ & $\mathrm{N} / \mathrm{S}$ & $\mathrm{N} / \mathrm{S}$ & $\mathrm{N} / \mathrm{N}$ & $\mathrm{N} / \mathrm{N}$ & $\mathrm{N} / \mathrm{N}$ & $\mathrm{N} / \mathrm{N}$ & $\mathrm{N} / \mathrm{N}$ & $\mathrm{N} / \mathrm{N}$ & $\mathrm{N} / \mathrm{N}$ \\
\hline $2009 B$ & $\mathrm{~N} / \mathrm{N}$ & $S / S$ & $\mathrm{~N} / \mathrm{N}$ & $S / S$ & $\mathrm{~N} / \mathrm{N}$ & $S / S$ & $\mathrm{~N} / \mathrm{N}$ & $S / S$ & $\mathrm{~N} / \mathrm{N}$ & $\mathrm{N} / \mathrm{N}$ & $\mathrm{N} / \mathrm{N}$ & $\mathrm{N} / \mathrm{N}$ \\
\hline $2009 C$ & $\mathrm{~N} / \mathrm{N}$ & $\mathrm{N} / \mathrm{N}$ & $\mathrm{N} / \mathrm{N}$ & $\mathrm{N} / \mathrm{N}$ & $\mathrm{N} / \mathrm{N}$ & $\mathrm{N} / \mathrm{N}$ & $\mathrm{N} / \mathrm{N}$ & $\mathrm{N} / \mathrm{N}$ & $\mathrm{N} / \mathrm{N}$ & $\mathrm{N} / \mathrm{N}$ & $\mathrm{N} / \mathrm{N}$ & $\mathrm{N} / \mathrm{N}$ \\
\hline 2009D & $\mathrm{N} / \mathrm{N}$ & $\mathrm{S} / \mathrm{N}$ & $\mathrm{N} / \mathrm{N}$ & $S / S$ & $\mathrm{~N} / \mathrm{S}$ & $\mathrm{N} / \mathrm{N}$ & $\mathrm{N} / \mathrm{N}$ & $\mathrm{N} / \mathrm{S}$ & $\mathrm{N} / \mathrm{N}$ & $\mathrm{N} / \mathrm{N}$ & $\mathrm{N} / \mathrm{N}$ & $\mathrm{N} / \mathrm{N}$ \\
\hline 2009E & $\mathrm{N} / \mathrm{N}$ & $\mathrm{N} / \mathrm{N}$ & $\mathrm{N} / \mathrm{N}$ & $\mathrm{N} / \mathrm{S}$ & $\mathrm{N} / \mathrm{S}$ & $\mathrm{S} / \mathrm{N}$ & $\mathrm{N} / \mathrm{N}$ & $\mathrm{N} / \mathrm{N}$ & $\mathrm{N} / \mathrm{N}$ & $\mathrm{N} / \mathrm{N}$ & $\mathrm{N} / \mathrm{N}$ & $\mathrm{N} / \mathrm{N}$ \\
\hline $2010 A$ & $\mathrm{~N} / \mathrm{N}$ & $\mathrm{S} / \mathrm{N}$ & $\mathrm{N} / \mathrm{N}$ & $\mathrm{N} / \mathrm{N}$ & $S / S$ & $\mathrm{~N} / \mathrm{N}$ & $\mathrm{N} / \mathrm{N}$ & $\mathrm{N} / \mathrm{S}$ & $\mathrm{N} / \mathrm{N}$ & $\mathrm{N} / \mathrm{N}$ & $\mathrm{N} / \mathrm{N}$ & $\mathrm{N} / \mathrm{N}$ \\
\hline 2010B & $\mathrm{N} / \mathrm{N}$ & $\mathrm{S} / \mathrm{N}$ & $\mathrm{N} / \mathrm{N}$ & $\mathrm{N} / \mathrm{N}$ & $\mathrm{N} / \mathrm{N}$ & $\mathrm{N} / \mathrm{N}$ & $\mathrm{N} / \mathrm{N}$ & $\mathrm{N} / \mathrm{N}$ & $\mathrm{N} / \mathrm{N}$ & $\mathrm{N} / \mathrm{N}$ & $\mathrm{N} / \mathrm{N}$ & $\mathrm{N} / \mathrm{N}$ \\
\hline $2010 C$ & $\mathrm{~N} / \mathrm{N}$ & $\mathrm{N} / \mathrm{N}$ & $\mathrm{N} / \mathrm{N}$ & $\mathrm{N} / \mathrm{N}$ & $\mathrm{N} / \mathrm{N}$ & $\mathrm{N} / \mathrm{N}$ & $\mathrm{N} / \mathrm{N}$ & $\mathrm{N} / \mathrm{N}$ & $\mathrm{N} / \mathrm{N}$ & $\mathrm{N} / \mathrm{N}$ & $\mathrm{N} / \mathrm{N}$ & $\mathrm{N} / \mathrm{N}$ \\
\hline 2010D & $\mathrm{N} / \mathrm{N}$ & $\mathrm{S} / \mathrm{N}$ & $\mathrm{N} / \mathrm{N}$ & $\mathrm{N} / \mathrm{N}$ & $\mathrm{N} / \mathrm{S}$ & $\mathrm{N} / \mathrm{N}$ & $\mathrm{N} / \mathrm{N}$ & $\mathrm{N} / \mathrm{N}$ & $\mathrm{N} / \mathrm{N}$ & $\mathrm{N} / \mathrm{N}$ & $\mathrm{N} / \mathrm{N}$ & $\mathrm{N} / \mathrm{N}$ \\
\hline $2011 \mathrm{~A}$ & $\mathrm{~N} / \mathrm{N}$ & $\mathrm{N} / \mathrm{N}$ & $\mathrm{N} / \mathrm{N}$ & $\mathrm{N} / \mathrm{N}$ & $S / S$ & $\mathrm{~N} / \mathrm{N}$ & $\mathrm{N} / \mathrm{N}$ & $\mathrm{N} / \mathrm{N}$ & $\mathrm{N} / \mathrm{N}$ & $\mathrm{N} / \mathrm{N}$ & $\mathrm{N} / \mathrm{N}$ & $\mathrm{N} / \mathrm{N}$ \\
\hline 2011B & $\mathrm{N} / \mathrm{N}$ & $\mathrm{N} / \mathrm{N}$ & $\mathrm{N} / \mathrm{N}$ & $\mathrm{N} / \mathrm{N}$ & $S / S$ & $S / S$ & $\mathrm{~N} / \mathrm{N}$ & $\mathrm{N} / \mathrm{N}$ & $\mathrm{N} / \mathrm{N}$ & $\mathrm{N} / \mathrm{N}$ & $\mathrm{N} / \mathrm{N}$ & $\mathrm{N} / \mathrm{N}$ \\
\hline $2011 C$ & $\mathrm{~N} / \mathrm{N}$ & $\mathrm{S} / \mathrm{N}$ & $\mathrm{N} / \mathrm{N}$ & $\mathrm{N} / \mathrm{N}$ & $\mathrm{S} / \mathrm{N}$ & $\mathrm{N} / \mathrm{N}$ & $\mathrm{N} / \mathrm{N}$ & $\mathrm{N} / \mathrm{N}$ & $\mathrm{N} / \mathrm{N}$ & $\mathrm{N} / \mathrm{N}$ & $\mathrm{N} / \mathrm{N}$ & $\mathrm{N} / \mathrm{N}$ \\
\hline 2011D & $\mathrm{N} / \mathrm{N}$ & $\mathrm{N} / \mathrm{N}$ & $\mathrm{N} / \mathrm{N}$ & $\mathrm{N} / \mathrm{N}$ & $S / S$ & $\mathrm{~N} / \mathrm{N}$ & $\mathrm{N} / \mathrm{N}$ & $\mathrm{N} / \mathrm{N}$ & $\mathrm{N} / \mathrm{N}$ & $\mathrm{N} / \mathrm{N}$ & $\mathrm{N} / \mathrm{N}$ & $\mathrm{N} / \mathrm{N}$ \\
\hline $2012 A$ & $\mathrm{~N} / \mathrm{N}$ & $S / S$ & $\mathrm{~S} / \mathrm{N}$ & $\mathrm{N} / \mathrm{N}$ & $\mathrm{N} / \mathrm{N}$ & $\mathrm{S} / \mathrm{N}$ & $\mathrm{N} / \mathrm{N}$ & $\mathrm{N} / \mathrm{N}$ & $\mathrm{N} / \mathrm{N}$ & $\mathrm{N} / \mathrm{N}$ & $\mathrm{N} / \mathrm{N}$ & $\mathrm{N} / \mathrm{N}$ \\
\hline 2012B & $\mathrm{N} / \mathrm{N}$ & $\mathrm{S} / \mathrm{N}$ & $\mathrm{N} / \mathrm{N}$ & $\mathrm{N} / \mathrm{N}$ & $S / S$ & $\mathrm{~N} / \mathrm{N}$ & $\mathrm{N} / \mathrm{N}$ & $\mathrm{S} / \mathrm{N}$ & $\mathrm{N} / \mathrm{N}$ & $\mathrm{N} / \mathrm{N}$ & $\mathrm{N} / \mathrm{N}$ & $\mathrm{N} / \mathrm{N}$ \\
\hline
\end{tabular}

$\mathrm{N}$ = Indicador não encontrado; $\mathrm{S}=$ Presença constatada do indicador. 
A seguir reuniram-se os dados consolidados, com as somas, apresentados na Tabela 2.

A soma total mostra o resultado de 308 ausências e 60 presenças. Os indicadores A2 (contribuição claramente delimitada), com 15 presenças; e BI (adiciona conhecimento teórico) com ig presenças foram os mais participativos. $\mathrm{O}$ indicador $\mathrm{A} 2$, na verdade, é uma exigência de toda investigação, não podendo ser considerada exatamente como uma contribuição das teses. O indicador Bi será discutido adiante, mas é possível adiantar que algumas teses que afirmam adição de conhecimento realizaram testes de modelo, tornando discutível a adição.

Tabela 2 Resultados sobre a presença ( $\mathrm{S}$ ) ou ausência $(\mathrm{N})$ de indicadores de originalidade em teses brasileiras de 2004 a 2013

\begin{tabular}{|lllllllllllll|} 
A1 & A2 & A3 & A4 & B1 & B2 & B3 & B4 & B5 & E1 & E2 & E3 & Soma \\
\hline $46 N$ & $31 \mathrm{~N}$ & $44 \mathrm{~N}$ & $37 \mathrm{~N}$ & $27 \mathrm{~N}$ & $37 \mathrm{~N}$ & $46 \mathrm{~N}$ & $40 \mathrm{~N}$ & $46 \mathrm{~N}$ & $46 \mathrm{~N}$ & $46 \mathrm{~N}$ & $46 \mathrm{~N}$ & $308 \mathrm{~N}$ \\
\hline OS & $15 \mathrm{~S}$ & $2 \mathrm{~S}$ & $9 \mathrm{~S}$ & $19 \mathrm{~S}$ & $9 \mathrm{~S}$ & $0 \mathrm{~S}$ & $6 \mathrm{~S}$ & $0 \mathrm{~S}$ & $0 \mathrm{~S}$ & $0 \mathrm{~S}$ & $0 \mathrm{~S}$ & $60 \mathrm{~S}$ \\
\hline
\end{tabular}

Em seguida realizou-se a mesma análise para a categoria Significância, com o resultado geral apresentado no Quadro 4 e os resultados consolidados apresentados na Tabela 3.

Quadro 4 Análise das contribuições apresentadas pelas teses brasileiras no período de ro anos, conforme indicadores de significância levantados na literatura

\begin{tabular}{|c|c|c|c|c|c|c|c|c|}
\hline \multirow[t]{2}{*}{ Tese } & \multicolumn{8}{|c|}{$\begin{array}{l}\text { Indicadores de Significância. } \mathrm{AC}=\text { Análise de Conteúdo; } \mathrm{CH}=\text { Palavra chave } \\
\text { encontrada no texto }\end{array}$} \\
\hline & B6 & B7 & C1 & $C_{2}$ & E4 & E5 & E6 & E7 \\
\hline & $\mathrm{AC} / \mathrm{CH}$ & $\mathrm{AC} / \mathrm{CH}$ & $\mathrm{AC} / \mathrm{CH}$ & $\mathrm{AC} / \mathrm{CH}$ & $\mathrm{AC} / \mathrm{CH}$ & $\mathrm{AC} / \mathrm{CH}$ & $\mathrm{AC} / \mathrm{CH}$ & $\mathrm{AC} / \mathrm{CH}$ \\
\hline $2004 A$ & $\mathrm{~N} / \mathrm{N}$ & $\mathrm{N} / \mathrm{N}$ & $S / S$ & $\mathrm{~S} / \mathrm{N}$ & $\mathrm{N} / \mathrm{N}$ & $\mathrm{S} / \mathrm{N}$ & $\mathrm{N} / \mathrm{N}$ & $\mathrm{N} / \mathrm{N}$ \\
\hline 2004B & $\mathrm{N} / \mathrm{N}$ & $\mathrm{N} / \mathrm{N}$ & $\mathrm{N} / \mathrm{S}$ & $\mathrm{N} / \mathrm{N}$ & $\mathrm{N} / \mathrm{N}$ & $\mathrm{N} / \mathrm{N}$ & $\mathrm{N} / \mathrm{N}$ & $\mathrm{N} / \mathrm{N}$ \\
\hline $2005 A$ & $\mathrm{~N} / \mathrm{N}$ & $\mathrm{N} / \mathrm{N}$ & $\mathrm{N} / \mathrm{S}$ & $\mathrm{N} / \mathrm{N}$ & $\mathrm{N} / \mathrm{N}$ & $\mathrm{N} / \mathrm{N}$ & $\mathrm{N} / \mathrm{N}$ & $\mathrm{N} / \mathrm{N}$ \\
\hline $2005 B$ & $\mathrm{~N} / \mathrm{N}$ & $\mathrm{N} / \mathrm{S}$ & $\mathrm{N} / \mathrm{S}$ & $\mathrm{N} / \mathrm{S}$ & $\mathrm{N} / \mathrm{N}$ & $\mathrm{S} / \mathrm{N}$ & $\mathrm{N} / \mathrm{N}$ & $\mathrm{N} / \mathrm{N}$ \\
\hline $2005 C$ & $\mathrm{~N} / \mathrm{N}$ & $\mathrm{N} / \mathrm{N}$ & $\mathrm{N} / \mathrm{S}$ & $\mathrm{N} / \mathrm{N}$ & $\mathrm{N} / \mathrm{N}$ & $\mathrm{N} / \mathrm{N}$ & $\mathrm{N} / \mathrm{N}$ & $\mathrm{N} / \mathrm{N}$ \\
\hline
\end{tabular}




\begin{tabular}{|c|c|c|c|c|c|c|c|c|}
\hline \multirow[t]{2}{*}{ Tese } & \multicolumn{8}{|c|}{$\begin{array}{l}\text { Indicadores de Significância. } \mathrm{AC}=\text { Análise de Conteúdo; } \mathrm{CH}=\text { Palavra chave } \\
\text { encontrada no texto }\end{array}$} \\
\hline & B6 & B7 & C1 & $C_{2}$ & E4 & E5 & E6 & E7 \\
\hline $2006 \mathrm{~A}$ & $\mathrm{~N} / \mathrm{N}$ & $\mathrm{N} / \mathrm{N}$ & $S / S$ & $\mathrm{~S} / \mathrm{N}$ & $S / S$ & $\mathrm{~N} / \mathrm{N}$ & $\mathrm{N} / \mathrm{N}$ & $\mathrm{N} / \mathrm{N}$ \\
\hline $2006 B$ & $\mathrm{~N} / \mathrm{N}$ & $\mathrm{S} / \mathrm{N}$ & $\mathrm{S} / \mathrm{N}$ & $\mathrm{S} / \mathrm{N}$ & $\mathrm{N} / \mathrm{N}$ & $\mathrm{S} / \mathrm{N}$ & $\mathrm{N} / \mathrm{N}$ & $S / S$ \\
\hline $2008 \mathrm{~A}$ & $\mathrm{~N} / \mathrm{N}$ & $\mathrm{N} / \mathrm{N}$ & $\mathrm{N} / \mathrm{N}$ & $\mathrm{N} / \mathrm{N}$ & $\mathrm{N} / \mathrm{N}$ & $\mathrm{N} / \mathrm{N}$ & $\mathrm{N} / \mathrm{N}$ & $\mathrm{N} / \mathrm{N}$ \\
\hline $2009 A$ & $\mathrm{~S} / \mathrm{N}$ & $\mathrm{S} / \mathrm{N}$ & $S / S$ & $\mathrm{~S} / \mathrm{N}$ & $\mathrm{N} / \mathrm{N}$ & $\mathrm{S} / \mathrm{N}$ & $\mathrm{N} / \mathrm{N}$ & $\mathrm{N} / \mathrm{N}$ \\
\hline 2009B & $\mathrm{N} / \mathrm{N}$ & $\mathrm{N} / \mathrm{N}$ & $\mathrm{N} / \mathrm{N}$ & $\mathrm{N} / \mathrm{N}$ & $\mathrm{N} / \mathrm{N}$ & $\mathrm{S} / \mathrm{N}$ & $\mathrm{N} / \mathrm{N}$ & $\mathrm{N} / \mathrm{N}$ \\
\hline $2009 C$ & $\mathrm{~N} / \mathrm{N}$ & $\mathrm{N} / \mathrm{N}$ & $\mathrm{N} / \mathrm{N}$ & $\mathrm{N} / \mathrm{N}$ & $\mathrm{N} / \mathrm{N}$ & $\mathrm{N} / \mathrm{N}$ & $\mathrm{N} / \mathrm{N}$ & $\mathrm{N} / \mathrm{N}$ \\
\hline 2009D & $\mathrm{N} / \mathrm{N}$ & $\mathrm{N} / \mathrm{S}$ & $\mathrm{S} / \mathrm{N}$ & $\mathrm{N} / \mathrm{N}$ & $\mathrm{N} / \mathrm{N}$ & $\mathrm{S} / \mathrm{N}$ & $\mathrm{N} / \mathrm{N}$ & $\mathrm{N} / \mathrm{N}$ \\
\hline $2009 E$ & $\mathrm{~N} / \mathrm{N}$ & $\mathrm{N} / \mathrm{N}$ & $\mathrm{N} / \mathrm{N}$ & $\mathrm{N} / \mathrm{N}$ & $\mathrm{N} / \mathrm{N}$ & $\mathrm{N} / \mathrm{N}$ & $\mathrm{N} / \mathrm{N}$ & $\mathrm{N} / \mathrm{N}$ \\
\hline $2010 A$ & $\mathrm{~N} / \mathrm{N}$ & $\mathrm{N} / \mathrm{N}$ & $\mathrm{S} / \mathrm{N}$ & $\mathrm{S} / \mathrm{N}$ & $S / S$ & $\mathrm{~S} / \mathrm{N}$ & $\mathrm{N} / \mathrm{N}$ & $\mathrm{N} / \mathrm{N}$ \\
\hline $2010 B$ & $\mathrm{~N} / \mathrm{N}$ & $\mathrm{S} / \mathrm{N}$ & $\mathrm{S} / \mathrm{N}$ & $\mathrm{N} / \mathrm{N}$ & $\mathrm{N} / \mathrm{N}$ & $\mathrm{S} / \mathrm{N}$ & $\mathrm{N} / \mathrm{N}$ & $\mathrm{N} / \mathrm{N}$ \\
\hline $2010 C$ & $\mathrm{~N} / \mathrm{N}$ & $\mathrm{N} / \mathrm{N}$ & $\mathrm{N} / \mathrm{N}$ & $\mathrm{N} / \mathrm{N}$ & $\mathrm{N} / \mathrm{N}$ & $\mathrm{N} / \mathrm{N}$ & $\mathrm{N} / \mathrm{N}$ & $\mathrm{N} / \mathrm{N}$ \\
\hline 2010D & $\mathrm{N} / \mathrm{N}$ & $\mathrm{N} / \mathrm{N}$ & $\mathrm{S} / \mathrm{N}$ & $\mathrm{N} / \mathrm{N}$ & $\mathrm{N} / \mathrm{N}$ & $\mathrm{N} / \mathrm{N}$ & $\mathrm{N} / \mathrm{N}$ & $\mathrm{S} / \mathrm{N}$ \\
\hline $2011 \mathrm{~A}$ & $\mathrm{~N} / \mathrm{N}$ & $\mathrm{S} / \mathrm{N}$ & $\mathrm{S} / \mathrm{N}$ & $\mathrm{S} / \mathrm{N}$ & $\mathrm{S} / \mathrm{N}$ & $\mathrm{N} / \mathrm{N}$ & $\mathrm{N} / \mathrm{N}$ & $\mathrm{S} / \mathrm{N}$ \\
\hline 2011B & $\mathrm{N} / \mathrm{N}$ & $\mathrm{S} / \mathrm{N}$ & $\mathrm{S} / \mathrm{N}$ & $\mathrm{N} / \mathrm{N}$ & $\mathrm{N} / \mathrm{N}$ & $\mathrm{S} / \mathrm{N}$ & $\mathrm{N} / \mathrm{N}$ & $\mathrm{S} / \mathrm{N}$ \\
\hline $2011 C$ & $\mathrm{~N} / \mathrm{N}$ & $\mathrm{N} / \mathrm{N}$ & $\mathrm{S} / \mathrm{N}$ & $\mathrm{N} / \mathrm{N}$ & $\mathrm{N} / \mathrm{N}$ & $\mathrm{N} / \mathrm{N}$ & $\mathrm{N} / \mathrm{N}$ & $\mathrm{S} / \mathrm{N}$ \\
\hline 2011D & $\mathrm{N} / \mathrm{N}$ & $\mathrm{N} / \mathrm{N}$ & $\mathrm{S} / \mathrm{N}$ & $S / S$ & $S / S$ & $\mathrm{~N} / \mathrm{N}$ & $\mathrm{N} / \mathrm{N}$ & $\mathrm{S} / \mathrm{S}$ \\
\hline $2012 A$ & $\mathrm{~N} / \mathrm{N}$ & $\mathrm{N} / \mathrm{N}$ & $X / X$ & $\mathrm{~N} / \mathrm{N}$ & $\mathrm{N} / \mathrm{S}$ & $\mathrm{N} / \mathrm{N}$ & $\mathrm{N} / \mathrm{N}$ & $\mathrm{N} / \mathrm{N}$ \\
\hline 2012B & $\mathrm{N} / \mathrm{N}$ & $\mathrm{S} / \mathrm{N}$ & $X / X$ & $\mathrm{~N} / \mathrm{N}$ & $S / S$ & $\mathrm{~S} / \mathrm{N}$ & $\mathrm{N} / \mathrm{N}$ & $\mathrm{S} / \mathrm{N}$ \\
\hline
\end{tabular}

$\mathrm{N}$ = Indicador não encontrado; $\mathrm{S}=$ Presença constatada do indicador.

Como se verifica na Tabela 3, a soma total é próxima do resultado obtido na Tabela 2, mas a distribuição interna é mais diversificada, ressaltando o indicador $\mathrm{CI}$ (utilidade no sentido de aplicação), com 23 presenças, mostrando a tendência de um foco gerencial das teses.

Tabela 3 Resultados sobre a presença $(\mathrm{S})$ ou ausência $(\mathrm{N})$ de indicadores de Significância em teses brasileiras de 2004 a 2013

\begin{tabular}{|lllllllll|}
\hline B6 & B7 & C1 & C2 & E4 & E5 & E6 & E7 & Soma \\
\hline $45 N$ & $38 N$ & $23 N$ & $37 N$ & $36 N$ & $36 N$ & $46 N$ & $37 N$ & $298 N$ \\
$1 S$ & $8 S$ & $23 S$ & $9 S$ & $10 S$ & $10 S$ & $0 S$ & $9 S$ & $70 S$ \\
\hline
\end{tabular}


A afirmativa orientadora do trabalho é que com a abertura do campo de Redes, sem um paradigma dominante, seriam encontradas diversas contribuições, em vários subtemas, de natureza teórica, metodológica e gerencial. Secundariamente, esperava-se encontrar uma linha de temática mais repetida na academia brasileira, considerando possíveis características diferenciais das redes locais.

A primeira constatação e resposta ao problema de pesquisa é que são raras as contribuições teóricas sobre o campo de Redes. As contribuições encontradas convergem nos esforços de confirmação de modelos; aproximação de conceitos (mas sem criar novos modelos) e teste de afirmativas em grupos selecionados.

A segunda resposta é que são raras as contribuições metodológicas, restringindo-se a algumas junções de técnicas, as quais não podem ser consideradas exatamente como inovações, já que a multiplicidade de formas de coleta e de análise é afirmada há algumas décadas na investigação de redes (TICHY; TUSHMAM; FOMBRUN, 1979). Nenhuma tese apresentou um novo instrumento de coleta e de análise, nenhuma abordagem diferenciada (por exemplo, um modelo específico de investigação considerando a complexidade do fenômeno), nenhum desenho de pesquisa que servisse como orientador de uma trilha de investigação.

Sobre contribuições gerenciais, são as que apresentam maior frequência relativa, comparadas com contribuições teóricas e metodológicas.

Para verificar um possível alinhamento das contribuições seguindo indicadores apenas nacionais refez-se os Quadros 3 e 4, utilizando os indicadores AI, A2, B2 e CI, que são os nacionais. O resultado tese a tese pode ser visto no Quadro 5 os dados consolidados podem ser vistos na Tabela 4. 
Quadro 5 As contribuições de teses brasileiras no período de 2004 a 2013, quando se consideram indicadores de fontes nacionais. $\mathrm{AC}=$ Análise de Conteúdo; $\mathrm{CH}=$ Palavra Chave

\begin{tabular}{|c|c|c|c|c|}
\hline Teses & A1 & $\mathbf{A} 2$ & B2 & C1 \\
\hline & $\mathrm{AC} / \mathrm{CH}$ & $\mathrm{AC} / \mathrm{CH}$ & $\mathrm{AC} / \mathrm{CH}$ & $\mathrm{AC} / \mathrm{CH}$ \\
\hline $2004 A$ & $\mathrm{~N} / \mathrm{N}$ & $\mathrm{N} / \mathrm{S}$ & $\mathrm{N} / \mathrm{N}$ & $S / S$ \\
\hline 2004B & $\mathrm{N} / \mathrm{N}$ & $\mathrm{N} / \mathrm{S}$ & $\mathrm{N} / \mathrm{N}$ & $\mathrm{N} / \mathrm{S}$ \\
\hline $2005 A$ & $\mathrm{~N} / \mathrm{N}$ & $\mathrm{N} / \mathrm{N}$ & $\mathrm{N} / \mathrm{N}$ & $\mathrm{N} / \mathrm{S}$ \\
\hline 2005B & $\mathrm{N} / \mathrm{N}$ & $\mathrm{N} / \mathrm{S}$ & $\mathrm{N} / \mathrm{N}$ & $\mathrm{N} / \mathrm{S}$ \\
\hline $2005 C$ & $\mathrm{~N} / \mathrm{N}$ & $\mathrm{N} / \mathrm{N}$ & $\mathrm{N} / \mathrm{N}$ & $\mathrm{N} / \mathrm{S}$ \\
\hline $2006 A$ & $\mathrm{~N} / \mathrm{N}$ & $S / S$ & $\mathrm{~N} / \mathrm{N}$ & $S / S$ \\
\hline 2006B & $\mathrm{N} / \mathrm{N}$ & $\mathrm{N} / \mathrm{N}$ & $\mathrm{N} / \mathrm{S}$ & $\mathrm{S} / \mathrm{N}$ \\
\hline $2008 \mathrm{~A}$ & $\mathrm{~N} / \mathrm{N}$ & $\mathrm{N} / \mathrm{N}$ & $\mathrm{N} / \mathrm{N}$ & $\mathrm{N} / \mathrm{N}$ \\
\hline $2009 A$ & $\mathrm{~N} / \mathrm{N}$ & $\mathrm{N} / \mathrm{N}$ & $\mathrm{N} / \mathrm{N}$ & $S / S$ \\
\hline 2009B & $\mathrm{N} / \mathrm{N}$ & $S / S$ & $S / S$ & $\mathrm{~N} / \mathrm{N}$ \\
\hline $2009 C$ & $\mathrm{~N} / \mathrm{N}$ & $\mathrm{N} / \mathrm{N}$ & $S / S$ & $\mathrm{~N} / \mathrm{N}$ \\
\hline 2009D & $\mathrm{N} / \mathrm{N}$ & $\mathrm{S} / \mathrm{N}$ & $\mathrm{N} / \mathrm{N}$ & $\mathrm{S} / \mathrm{N}$ \\
\hline $2009 E$ & $\mathrm{~N} / \mathrm{N}$ & $\mathrm{N} / \mathrm{N}$ & $\mathrm{S} / \mathrm{N}$ & $\mathrm{N} / \mathrm{N}$ \\
\hline $2010 A$ & $\mathrm{~N} / \mathrm{N}$ & $\mathrm{S} / \mathrm{N}$ & $\mathrm{N} / \mathrm{N}$ & $\mathrm{S} / \mathrm{N}$ \\
\hline 2010B & $\mathrm{N} / \mathrm{N}$ & $\mathrm{S} / \mathrm{N}$ & $\mathrm{N} / \mathrm{N}$ & $\mathrm{S} / \mathrm{N}$ \\
\hline $2010 C$ & $\mathrm{~N} / \mathrm{N}$ & $\mathrm{N} / \mathrm{N}$ & $\mathrm{N} / \mathrm{N}$ & $\mathrm{N} / \mathrm{N}$ \\
\hline 2010D & $\mathrm{N} / \mathrm{N}$ & $\mathrm{S} / \mathrm{N}$ & $\mathrm{N} / \mathrm{N}$ & $\mathrm{S} / \mathrm{N}$ \\
\hline $2011 \mathrm{~A}$ & $\mathrm{~N} / \mathrm{N}$ & $\mathrm{N} / \mathrm{N}$ & $\mathrm{N} / \mathrm{N}$ & $\mathrm{S} / \mathrm{N}$ \\
\hline 2011B & $\mathrm{N} / \mathrm{N}$ & $\mathrm{N} / \mathrm{N}$ & $S / S$ & $\mathrm{~S} / \mathrm{N}$ \\
\hline $2011 C$ & $\mathrm{~N} / \mathrm{N}$ & $\mathrm{S} / \mathrm{N}$ & $\mathrm{N} / \mathrm{N}$ & $\mathrm{S} / \mathrm{N}$ \\
\hline 2011D & $\mathrm{N} / \mathrm{N}$ & $\mathrm{N} / \mathrm{N}$ & $\mathrm{N} / \mathrm{N}$ & $\mathrm{S} / \mathrm{N}$ \\
\hline $2012 A$ & $\mathrm{~N} / \mathrm{N}$ & $S / S$ & $\mathrm{~S} / \mathrm{N}$ & $X / X$ \\
\hline 2012B & $\mathrm{N} / \mathrm{N}$ & $\mathrm{S} / \mathrm{N}$ & $\mathrm{N} / \mathrm{N}$ & $X / X$ \\
\hline
\end{tabular}

$\mathrm{N}$ = Indicador não encontrado; $\mathrm{S}=$ Presença constatada do indicador. 
Tabela 4 Resultados sobre a presença $(\mathrm{S})$ ou ausência $(\mathrm{N})$ de indicadores brasileiros de Originalidade e Significância, em teses brasileiras de 2004 a 2013

\begin{tabular}{|llllll|}
\hline A1 & A2 & B2 & C1 & Soma Originalidade & Soma Significância \\
\hline $46 \mathrm{~N}$ & $31 \mathrm{~N}$ & $37 \mathrm{~N}$ & $23 \mathrm{~N}$ & $114 \mathrm{~N}$ & $23 \mathrm{~N}$ \\
\hline $0 \mathrm{~S}$ & $15 \mathrm{~S}$ & $9 \mathrm{~S}$ & $23 \mathrm{~S}$ & $24 \mathrm{~S}$ & $23 \mathrm{~S}$ \\
\hline
\end{tabular}

Nesta nova configuração verifica-se que os resultados de Originalidade considerando apenas os critérios brasileiros são próximos dos critérios globais, com cerca de I7\% e de I6\%, respectivamente. Quanto à Significância observa-se uma melhora acentuada do indicador nacional contra o global, com $50 \%$ de presença do primeiro e $19 \%$ no global. Como existe apenas I indicador nacional (Cr, que é comum ao nacional e internacional) e um total de 8 indicadores no global, a análise da mudança deve ser relativizada. Uma interpretação possível é sobre a subjetividade de percepção do orientador e do pesquisador sobre a sua tese apresentar utilidade, aplicação e importância para ser publicada.

Os resultados das análises são interpretados com base em quatro perspectivas:

a. Os coordenadores e orientadores dos programas adaptam-se aos recursos humanos existentes e seguem adiante com as teses, mesmo sabendo das limitações dos resultados. A rigidez de regras e normas e as pressões para produção que recaem sobre os programas impõem restrições à liberdade de pensamento e ação do orientador e do pesquisador, optando-se pelo caminho da tese ser uma dissertação um pouco mais qualificada. Essa interpretação indica a possibilidade (talvez até a necessidade) de uma pesquisa qualitativa com orientadores de teses.

b. Há certo desconhecimento sobre o que é uma contribuição científi$\mathrm{ca}$, no sentido de teoria do conhecimento. Uma das teses, que confirmou um modelo existente, continha uma ata anexada, com elogios sobre a qualidade do trabalho e sua contribuição científica, obtendo nota dez. Fica a dúvida sobre qual a contribuição científica quando 
uma tese confirma um modelo, utilizando dados de pesquisa local. A leitura da parte de teorias utilizadas mostrou esse desconhecimento quando o pesquisador coloca, por exemplo, o tipo de estrutura da rede (vertical, ou horizontal) como teoria de base. Ainda nessa linha, não se encontrou nenhuma discussão específica sobre o que seria uma contribuição, no sentido de conhecimento científico. É como se o termo fosse de domínio comum, mas não é o que transparece nas 23 teses.

c. Os envolvidos na tarefa (coordenadores, orientadores, doutorandos, secretarias, reitores) seguem seus próprios critérios sobre o que constitui uma contribuição, conforme interesses e recursos do seu programa. Uma confirmação de uma teoria baseada na investigação de uma rede local, por exemplo, pode ser vantajosa e interessante para a universidade que tenha vínculos com instituições e o governo local. A análise de um cluster industrial de um município, ou de uma rede solidária, por exemplo, podem resultar em benefícios gerenciais locais. Para esses casos talvez o critério estrito de contribuição científica fique em segundo plano.

d. Os critérios de contribuição de teses são inadequados para a Administração, já que indicadores como desvelar raramente aparecem em trabalhos nessa ciência. Eles são mais apropriados a investigações da Antropologia, Sociologia e Psicologia.

Os indicadores de originalidade na categoria E, que tratam de revelação, recuperação e reinterpretação, deram resultado zero. Fica o questionamento sobre a validade do critério, o que também enseja uma pesquisa qualitativa. 


\section{CONSIDERAÇÕES FINAIS}

O objetivo do trabalho consistiu em analisar criticamente as contribuições expressas nas teses brasileiras sobre Redes, no período de 2004 a 2013. Considerando o leque de teorias, modelos e afirmativas sobre as redes de negócios, construiu-se a pergunta orientadora sobre a natureza das contribuições das teses brasileiras e o resultado esperado era um leque de contribuições teóricas e modos de pesquisa, considerando a fragmentação das teorias aplicadas e a complexidade do fenômeno.

Os critérios de seleção com base no de bancos de dados nacionais resultaram no aceite de 23 teses, analisadas conforme 20 indicadores construídos baseados na literatura acadêmica internacional e brasileira. A resposta encontrada é que são praticamente inexistentes as contribuições teóricas; existem algumas contribuições metodológicas, na linha de ajustes de técnicas e existem algumas sugestões gerenciais para grupos locais investigados. A dominância é de trabalhos confirmatórios de modelos existentes, com ausência de discussão e crítica teórica.

Como tentativa de explicar os resultados, foram apresentadas quatro interpretações.

a. Os coordenadores e orientadores dos programas adaptam-se aos recursos humanos existentes. A equação do conhecimento e da contribuição da tese fica invertida, colocando-se o recurso disponível em primeiro plano e condicionando-se o resultado ao recurso, ao invés de qualificar o recurso. Pressões para produção e indicadores de quantidade de defesas de doutorandos podem ser algumas das forças de influência.

b. Os envolvidos na tarefa (coordenadores, orientadores, doutorandos, secretarias, reitores) seguem seus próprios critérios sobre o que constitui uma contribuição, conforme interesses e recursos do seu programa. Esta interpretação é complementar à anterior, sendo mais ampla no sentido de estratégia da instituição de ensino. Por exemplo, uma universidade que se insere num programa de desenvolvimento local pode colocar como objetivo principal os resultados e aplicações locais, como estratégia de desenvolvimento do seu programa. 
c. Há desconhecimento sobre o que é uma contribuição científica, no sentido de teoria do conhecimento. Em nenhuma das teses analisadas encontrou-se alguma discussão sobre conhecimento, linhas de teoria do conhecimento e qual seria o caminho de contribuição ao conhecimento daquela tese. Nem mesmo os grandes sistemas de conhecimento que servem de apoio para a Administração, como sistemas da Psicologia, da Sociologia, da Antropologia e da Economia são comentados.

d. Os critérios de contribuição de teses são inadequados para a Administração. Alguns indicadores, tais como revelar o escondido, causar surpresa, ter impacto na vida social podem ser adequados para outras áreas (como Antropologia e Comunicação), mas não servem como orientadores de trabalhos em Administração e seu campo de Redes. Por outro lado, embora esta linha de argumentação tenha alguma lógica, os resultados totais nos Quadros 3 e 4 e nas Tabelas 2 e 3 não deixam dúvida que há ausência em quase todos os itens. A retirada de dois, ou três deles que resultam em soma zero de contribuição pode ser apenas um artifício de arranjo de dados. Senão, como explicar que o critério A1- Originalidade do Trabalho tenha resultado zero?

Considerando a relevância do tema de Redes; considerando a necessidade de existir uma marca, ou linha de investigação brasileira; considerando as exigências colocadas em congressos e revistas internacionais qualificadas (que definem claramente o que é uma contribuição científica) e considerando a importância dos programas de pós-graduação voltados para o tema de Redes de criarem linhas mais claras de como contribuir cientificamente para o campo; entende-se que o resultado negativo encontrado serve como sinal de alerta.

O Quadro I, se for lido sem as informações sobre o objetivo do artigo, pode ser classificado com um quadro sobre os temas de dissertações, já que predominam testes de validade de modelos existentes e sugestões gerenciais.

Assim, respondendo às questões colocadas na discussão inicial, concluise que não há contribuição ao conhecimento com base nas teses brasileiras, quando se considera o critério de originalidade, de algo inédito, ainda não 
realizado. Dos 20 indicadores selecionados, sendo I2 sobre originalidade e 8 sobre significância, os indicadores AI, B3, B5, E2 e E3 foram zerados para as 23 teses.

A dominância de estudos de universidades do sul do País, atreladas a programas políticos e sociais de desenvolvimento local, pode ser uma das explicações para a tendência de trabalhos gerenciais.

A geração de novos conhecimentos, seja numa linha positivista contemporânea de experimentação e erro, como em Popper (1974), seja numa linha fenomenológica de imersão no fenômeno, como em MerleauPonty (1994) só para citar dois extremos; exige aquele passo adiante, aquela proposição que vai além do conhecido. Na complexidade do fenômeno das redes e no leque de abordagens possíveis, os resultados indicam que algo não está ajustado na realização e conclusões das teses brasileiras.

Um caminho possível de aprofundamento do tema seria realizar uma pesquisa qualitativa, com orientadores e coordenadores de programas. $\mathrm{Na}$ linha de investigação dos egressos, Valadão Júnior e Rodrigues (20I2) concluíram que os cursos de pós-graduação são percebidos pelos alunos como formadores de pesquisadores, mais do que como formadores de educadores. A dúvida que se levanta é sobre quais competências de pesquisador estão sendo (ou percebidas como sendo) desenvolvidas nessas pessoas, seja no mestrado, seja no doutorado. 


\section{REFERÊNCIAS}

ABNT - ASSOCIAÇÃO BRASILEIRA DE NORMAS TÉCNICAS. NBR 14724: Informação e documentação: citações em documentos. Rio de Janeiro, 2005.

ASTI-VERA, A. Metodologia de pesquisa científica. Porto Alegre: Globo, 1980.

AXELROD, R. An evolutionary approach to norms. American Political Science Review, v.80, n.4, p.1095-1111, 1986.

BARDIN, L. Análise de Conteúdo. Lisboa: Edições 70, 1977.

BERTERO, C.; CALDAS, M.; WOOD, T. Produção Científica em Administração de Empresas: Provocações, insinuações e contribuições para um debate local. Revista de Administração Contemporânea, v.3, n.1, p.147-178, 1999.

BITTI, P. R.; ZANI, B. A Comunicação como Processo Social. Lisboa: Editorial Estampa, 1993. BURT, R. Positions in networks. Social Forces, v.55, n.1, p.93-122, 1976.

CASTTELS, M. Materials for an exploratory theory of the network society. British Journal of Sociology, v.51, n.1, p.5-24, 2000.

CASTRO, C. M. Estrutura e apresentação de publicações científicas. São Paulo: McGraw-Hill, 1978.

CASTRO, C. M. Memórias de um orientador de tese. In: BIANCHETTI, L.; MACHADO, A. (Org.). A bússola do escrever: desafios e estratégias na orientação de teses e dissertações. São Paulo: Cortez, 2002.

CHARLES STURT UNIVERSITY. Higher Degree by Research Candidates Information Guide. Disponível em: < http://www.csu.edu.au/research/support/research-students/my-hdr/ making-progress/writing-your-thesis $>$. Acesso em: 23/04/2013.

CLEMEN, R. T. Making hard decisions. Duxbury: Belmont, 1996.

DELEUZE, G.; GUATTARI, F. Mil Platôs. São Paulo: Editora 34, 2000.

ECO, U. Como se faz uma tese. São Paulo: Perspectiva, 2008.

GIGLIO, E. M. Análise e crítica da metodologia presente nos artigos brasileiros sobre redes de negócios e uma proposta de desenvolvimento. In: ENEO, 6., 2010. Florianópolis. Anais... Florianópolis: Anpad, 2010.

GOLEMBIEWSKI, R. T. The Small Group: An Analysis of Research Concepts and Operations. Chicago: The University of Chicago Press, 1962.

GRANDORI, A.; SODA, G. Inter-firm networks: Antecedents, mechanisms and forms. Organization Studies, v.16, n.2, p.183-214, 1995.

GRANOVETTER, M. Economic action and social structure: The problem of embeddedness. American Journal of Sociology, v.91, n.3, p.481-510, 1985.

GROSS, J.; YELLEN, J. Handbook of graph theory. New York: CRC Press, 2004. 
HALINEN, A.; SALMI, A.; HAVILA, V. From dyadic change to changing business networks: An analytical framework. Journal of Management Studies, v.36, n.6, p.779-794, 1999.

KUHN, T. The Structure of Scientific Revolutions, revised edition, Chicago: The University of Chicago Press, 1970.

JONES, C.; HESTERLY, W.; BORGATTI, S. A general theory of network governance: exchange conditions and social mechanisms. Academy of Management Journal, v.22, n.4, p.911-945, 1997.

LARSON, A.; STARR, J. A Network Model of Organization Formation, Entrepreneurship: Theory and Practice, v. 2, n.17, p.5-15, 1993.

LOVITTS, B. E.; WERT, E. Developing Quality Dissertations in the Social Sciences: A Graduate Student's Guide to Achieving Excellence. Sterling, VA: Stylus Publishing, 2009.

MARQUES, M. A orientação da pesquisa nos programas de pós-graduação. In Seminário de Pesquisa em Educação, 3., 2000. Porto Alegre. Anais... Porto Alegre, 2000.

MARTINS, G. Manual para elaboração de monografias e dissertações, 3.ed. São Paulo: Atlas, 2002.

MATURANA, H.; VARELA, F. A árvore do conhecimento. Campinas: Editorial Psy, 1995.

MERLEAU-PONTY, M. Fenomenologia da percepção. São Paulo: Martins Fontes, 1994.

MILES, R.; SNOW, C. Network organizations: New concepts for new forms. California Management Review, v.28, n.1, p.62-73, 1986.

MONASH UNIVERSITY. Handbook for Doctoral Degrees. Disponível em: $<$ http://www. monash.edu.au/migr/research-degrees/handbook $>$. Acesso em: 23/04/2013.

NOHRIA, N.; ECLES, R. Networks and organizations: Structure, form, and action. Boston: Harvard Business School, 1992.

POPPER, K. A sociedade aberta e seus inimigos. Belo Horizonte: Itatiaia, 1974.

POLANYI, K.; ARENSBERG, C.; PEARSON, H. Trade and Market in the Early Empires. New York: Free Press, 1957.

POWELL, W; SMITH-DOERR, L. Networks and Economic Life. In: SMELSER, N.; SWEDBERG, R. (Orgs.). Handbook of Economic Sociology, Princeton, NJ: Princeton University Press, p.368-402, 1994.

PRODANOV, C.; FREITAS, E. Metodologia do trabalho científico: métodos e técnicas da pesquisa e do trabalho acadêmico. 2.ed. Novo Hamburgo: Feevale, 2013.

PROVAN, K. Embeddeness, Interdependence, and opportunism in Organizational Supplier-Buyer networks. Journal of Management, v.19, n.4, p.841-856, 1993.

SACOMANO NETO, M. Morfologia, propriedades e posicionamentos das redes: contribuições às análises interfirmas. In: Simpósio de Engenharia de Produção, 11., 2004. Bauru/SP; Anais... Bauru/SP: UNESP, 2004.-

SALOMON, G. Can we affect cognitive skills through media? A hypothesis and findings. AV Communication Review, v.20, n.4, p.401-422, 1972. 
SELEME, A.; ORSSATO, R. A construção social da realidade organizacional: a tradição macro-analítica dos estudos organizacionais. In: EnANPAD, 14., 1990. Belo Horizonte. Anais... Belo Horizonte: Anpad, 1990.

SEVERINO, A. Metodologia do trabalho científico. 23.ed. São Paulo: Cortez, 2007.

SUCUPIRA, N. 1965. Definição dos cursos de pós-graduação, Disponível em:

$<$ http://www.capes.gov.br/images/stories/download/legislacao/Parecer_CESU_9771965. pdf> Acesso em: 07/08/2013.

THEÓPHILO, C.; IUDÍCIBUS, S. Uma Análise Crítico-Epistemológica da Produção Científica em Contabilidade no Brasil. Revista Contabilidade, Gestão e Governança, v8, n.2, p.147-173, 2005.

TICHY, N.; TUSHMAM, M.; FOMBRUN, C. Social Networks Analysis for Organizations. Academy of Management Review, v.4, n.4, p.507-519, 1979.

UFLA - UNIVERSIDADE FEDERAL DE LAVRAS. Manual de normalização e estrutura de trabalhos acadêmicos: TCC, monografia, dissertações e teses, 2010.

UFMG - UNIVERSIDADE FEDERAL DE MINAS GERAIS. Manual do Aluno Curso de Doutorado em Administração, 2013.

UFV - UNIVERSIDADE FEDERAL DE VIÇOSA. Manual de normalização de trabalhos acadêmicos, 2010.

UNIVERSITY OF OTTAWA. What exactly is a thesis or a research paper. Disponível em: $<$ http://www.grad.uottawa.ca/regulations/thesis_research/manual/definition. html\#thesis. $>$ Acesso em: 12/04/2013.

UNIVERSITY OF YORK. Writing a thesis in the social sciences. Disponivel em http://www. york.ac.uk/about/organisation/governance/governance-documents/ordinances-andregulations/regulation-2/. Acesso em: 12/04/2013.

USP - UNIVERSIDADE DE SÃO PAULO. Manual para Formatação e Edição de Dissertações e Teses, 2008.

VALADÃO JUNIOR, V.; RODRIGUES, H. Competências na Pós Graduação: O olhar dos egressos. Revista Administração: Ensino e Pesquisa, v.13, n.2, p.325-354, 2012.

WEGNER, D.; PADULA, A. A influência de fatores contextuais na governança de redes interorganizacionais. Gestão \& Planejamento, v.14, n.1, p.116-136, 2013.

WHETTEN, D. O que Constitui uma Contribuição Teórica? Revista de Administração de Empresas, v.43, n.3, p.69-73, 2003.

WILLIAMSON, O. The Economics of Organization: The Transaction Cost Approach. American Journal of Sociology, v.87, n.3, p.548-577, 1981.

WITTMANN, M. L.; DOTTO, D. R.; WEGNER, D. Redes de empresas: um estudo de redes de cooperação do Vale do Rio Pardo e Taquari no estado do Rio Grande do Sul. REDES, v.13, n.1, p.160-180, 2008. 


\section{DADOS DOS AUTORES}

\section{EDUARDO JORGE BRANCO VIEIRA BARCELOS ${ }^{\star}$}

eduardobrancobarcelos@gmail.com

Mestrando em Administração pela UNIP

Instituição de vinculação: Universidade Paulista

São Paulo/SP - Brasil

Áreas de interesse em pesquisa: Estratégia, Capacidades Dinâmicas/RBV e Redes de Negócios, Alianças/Governança.

* Rua Dr. Bacelar, 1212 Vila Clementino São Paulo/SP 04026-002

\section{RICARDO LERCHE ELEUTÉRIO ricardo.eleuterio@uol.com.br}

Mestrando em Administração pela UNIP

Instituição de vinculação: Universidade Paulista

São Paulo/SP - Brasil

Áreas de interesse em pesquisa: Estratégia e Internacionalização.

ERNESTO MICHELANGELO GIGLIO ernesto.giglio@gmail.com

Doutor em Administração pela Universidade de São Paulo

Instituição de vinculação: Universidade Paulista

São Paulo/SP - Brasil

Áreas de interesse em pesquisa: Redes de negócios e de cooperação. 